Correction

\title{
Correction: Ho, MT., et al. The Internal Capability of Vietnam Social Sciences and Humanities: A Perspective from the 2008-2019. Publications 2020, 8(2), 32
}

\author{
Manh-Toan Ho ${ }^{1,2, *(\mathbb{D})}$, Thu-Trang Vuong ${ }^{3, *}$, Thanh-Hang Pham ${ }^{4,5}{ }^{\circledR}$, Anh-Phuong Luong ${ }^{2,6} \mathbb{C}^{\text {, }}$ \\ Thanh-Nhan Nguyen ${ }^{2,6}\left(\mathbb{D}\right.$ and Quan-Hoang Vuong ${ }^{1, *} \mathbb{( 1 )}$ \\ 1 Centre for Interdisciplinary Social Research, Phenikaa University, Yen Nghia Ward, Ha Dong District, \\ Hanoi 100803, Vietnam \\ 2 A.I. for Social Data Lab, Vuong \& Associates, 3/161 Thinh Quang, Dong Da District, Hanoi 100000, Vietnam; \\ phuongla.yrc@gmail.com (A.-P.L.); nhanthanhnguyen20@gmail.com (T.-N.N.) \\ 3 Sciences Po Paris, 75337 Paris, France \\ 4 Faculty of Management and Tourism, Hanoi University, Km9, Nguyen Trai Road, Thanh Xuan, \\ Hanoi 100803, Vietnam; hangpt@hanu.edu.vn \\ 5 School of Business, RMIT Vietnam University, Hanoi 100000, Vietnam \\ 6 A.I. for Social Data Lab, Foreign Trade University, 91 Chua Lang Street, Dong Da District, \\ Hanoi 100000, Vietnam \\ * Correspondence: toan.homanh@phenikaa-uni.edu.vn (M.-T.H.); thutrang.vuong@sciencespo.fr (T.-T.V.); \\ hoang.vuongquan@phenikaa-uni.edu.vn (Q.-H.V.)
}

Received: 7 July 2020; Accepted: 8 July 2020; Published: 9 July 2020

The authors' wish to change the affiliations on Page 1 of their paper [1] from:

Author's name: Anh-Phuong Luong

Affiliations: A.I for Social Data Lab, Vuong \& Associates, 3/161 Thinh Quang, Dong Da District, Hanoi 100000, Vietnam; A.I. for Social Data Lab, Foreign Trade University, 91 Chua Lang street, Dong Da district, Hanoi 100000, Vietnam

And;

Author's name: Thanh-Nhan Nguyen

Affiliations: A.I for Social Data Lab, Vuong \& Associates, 3/161 Thinh Quang, Dong Da District, Hanoi 100000, Vietnam; A.I. for Social Data Lab, Foreign Trade University, 91 Chua Lang street, Dong Da district, Hanoi 100000, Vietnam

to the correct version, as follows: 


\section{Author's name: Anh-Phuong Luong}

Affiliation: ${ }^{2}$ A.I for Social Data Lab, Vuong \& Associates, 3/161 Thinh Quang, Dong Da District, Hanoi 100000, Vietnam; and ${ }^{6}$ Foreign Trade University, 91 Chua Lang street, Dong Da district, Hanoi 100000, Vietnam

And;

Author's name: Thanh-Nhan Nguyen

Affiliation: ${ }^{2}$ A.I for Social Data Lab, Vuong \& Associates, 3/161 Thinh Quang, Dong Da District, Hanoi 100000, Vietnam; and ${ }^{6}$ Foreign Trade University, 91 Chua Lang street, Dong Da district, Hanoi 100000, Vietnam

The authors apologize for any inconvenience brought to readers. The changes do not affect the scientific results. The manuscript will be updated and the original will remain online on the article webpage, with a reference to this Correction.

\section{References}

1. Ho, M.-T.; Vuong, T.-T.; Pham, T.-H.; Luong, A.-P.; Nguyen, T.-N.; Vuong, Q.-H. The Internal Capability of Vietnam Social Sciences and Humanities: A Perspective from the 2008-2019 Dataset. Publications 2020, 8, 32. [CrossRef]

(C) 2020 by the authors. Licensee MDPI, Basel, Switzerland. This article is an open access article distributed under the terms and conditions of the Creative Commons Attribution (CC BY) license (http://creativecommons.org/licenses/by/4.0/). 